\title{
РЕЗУЛЬТАТЫ ПРИМЕНЕНИЯ НОВЫХ ПОДХОДОВ \\ К КЛАССИФИКАЦИИ ПОВРЕЖДЕНИЙ И ЛЕЧЕНИЮ ПРИ СОЧЕТАННОЙ ТРАВМЕ У ДЕТЕЙ
}

Колтакова Мария Павловна студент

Перцева Мария Владимировна

ординатор

Научный руководитель: Вечёркин Владимир Александрович

д.м.н., профессор

ФГБОУ ВО ВГМУ им. Н.Н. Бурденко МЗ РФ

\begin{abstract}
Аннотация: Пострадавшие с сочетанной травмой нуждаются в исключительно быстром определении степени тяжести повреждений и составлении плана лечения. Существует множество шкал для классификации травм, в том числе, в детской хирургии. В работе врача неотложной помощи важно иметь точный алгоритм и пользоваться наиболее передовыми методами диагностики и лечения. Рассмотрена возможность применения международных шкал использование новых методов лечения в практике детского хирурга многопрофильного стационара.
\end{abstract}

Ключевые слова: сочетанная травма, метод Поединцева-Вороновой, гипербарическая оксигенация, Injury Severity Score, Abbreviated Injury Scale Score, центральная гемодинамика, тяжесть состояния.

\section{Koltakova Maria Pavlovna Pertseva Maria Vladimirovna Scientific advisor: Vecherkin Vladimir Alexandrovich}

\begin{abstract}
Patients with concomitant trauma require extremely rapid determination of the severity of the injuries and the preparation of a treatment plan. There are many scales for classifying injuries, including in pediatric surgery. In the work of an emergency doctor, it is important to have an accurate algorithm and use the most advanced methods of diagnosis and treatment. The possibility of applying the international scales of the use of new methods of treatment in the practice of a pediatric surgeon in a multidisciplinary hospital is considered.

Key words: combined trauma, Poedincev-Voronova method, hyperbaric oxygenation, Injury Severity Score, Abbreviated Injury Scale Score, central hemodynamics, severity of the condition.
\end{abstract}


Введение. Залогом успешного лечения и минимизации риска осложнений является быстрая, но при этом эффективная оценка тяжести повреждений у ребенка с диагнозом «сочетанная травма». На данный момент существует более 50 подобных шкал. Все они обладают своими достоинствами и недостатками. Задачей детского хирурга является наиболее скоро и эффективно оценить состояние тяжести ребенка и разработать план лечения [1, с. 18]. Международные шкалы AIS и ISS пока не получили широкого признания и распространения в Российской детской хирургической практике. Но они привлекли наше внимание простотой и удобством применения [2, с.12].

Цель - анализ возможности применения международных шкал AIS и ISS для оценки состояния пострадавших в практике детского хирурга многопрофильного стационара.

Материалы и методы. В клинике детской хирургии ВГМУ им. Н.Н. Бурденко в период с 2015 года по 2019 года находился под наблюдением 251 ребенок с сочетанной травмой в возрасте от 1 года до 17 лет, из них 160 (64\%) мальчиков и 91 девочка (36\%). Травмы были получены детьми в результате ДТП и в быту - по 81 случай (33\%), на улице - 38 (16\%), падение с высоты $19(8 \%)$, в школе - 12 (5\%). В результате криминальных действий зарегистрировано 9 случаев (4\%), при попытке суицида и укусе собаки 2 пациента (по 1 случаю - 0,5\%).

Для оценки уровня сознания пользовались шкалой Глазго (GCS). У 184 детей было зарегистрировано ясное сознание, 23 ребенка - доставлены в состоянии оглушения, 16 - сопора, 26 - в состоянии комы 1, 2, 3 степени.

Черепно-мозговая травма разной степени тяжести была зафиксирована у 100\% детей. Травмы скелета обнаружены у 74,3\% больных, ушиб легких - у 44\%, разрыв легких - у 17,8\%, ушиб сердца - у 0,9\%, ушиб органов брюшной полости - у 78\%, разрыв селезенки - у 8,9\%, переломы лицевого отдела черепа - у 14\% пострадавших.

Также все случаи, вне зависимости от стандартного протокола оценки тяжести повреждений в приемном отделении, были проклассифицированы по шкалам AIS и ISS в Европейской и Российской модификации.

AIS - Abbreviated Injury Scale Score - сокращенная шкала тяжести повреждений. Впервые введена в 1969 году. По данной шкале 1 балл присваивается легким повреждениям, 2 балла - повреждениям средней тяжести, 3 балла - тяжелым повреждениям, 4 балла - очень тяжелым, 5 баллов - крайне тяжелым, 6 баллов - терминальные повреждения [2, с. 12]. 
ISS - Injury Severity Score - шкала тяжести повреждений Baker S.P. 1974г. - каждой из анатомических областей присваивается степень тяжести по AIS, которая возводится в квадрат. Три наиболее высоких из полученных баллов суммируются. Оценка происходит по следующей шкале: 0-8 баллов легкие повреждения 9-15 баллов - средней тяжести 16 -24 баллов - тяжелые $>24$ баллов - крайне тяжелые [2, с. 12]. Впоследствии эти результаты были сопоставлены с данными дополнительных методов исследования, полученными при оценке состояния по стандартному протоколу приемного отделения.

Шкала Injury Severity Score имеет две вариации. Первая признанная мировым сообществом, вторая - модифицированная в Российской Федерации. Они отличаются по количеству анатомических областей, где происходят оцениваемые повреждения [2, с. $12-13 ; 3$, с. 8]. В модификации мирового сообщества учитывается шесть анатомических областей:

1. Голова и шея

2. Лицо

3. Грудь

4. Живот

5. Таз и конечности

6. Мягкие ткани

В российской модификации учитывается семь анатомических областей:

1. Голова

2. Шея

3. Грудь

4. Живот

5. Таз

6. Конечности

7. Позвоночник

Пациентам проводился мониторинг жизненно важных функций, ЭКГ, УЗИ, РКТ, МРТ, измерение ВЧД.

Из лабораторных методов исследования применялись: ОАК, ОАМ, КЩС в динамике, электролиты, биохимический анализ крови, коагулограмма, определение группы и резус-фактора крови, исследование ликвора $[4$, с. $61 ; 5$, c. 83-84].

Оценку параметров центральной гемодинамики (ЦГ) осуществляли методом Поединцева-Вороновой аппаратом «Кардиокод» при поступлении в 
приемное отделение, на 3-и, 5-е сутки и вплоть до нормализации гемодинамики. Данный метод основан на синхронизации методов электрокардиограммы и реограммы с восходящей аорты, с высокой точностью характеризует фазовые сигналы, позволяет не инвазивно измерять основные параметры гемодинамики с возможностью качественной оценки функционального состояния сердечнососудистой системы. Оценке подлежали следующие показатели: ударный объем (УО), минутный объем кровообращения (МОК), сократительная функция предсердий (систола предсердий), объем крови притекающий в желудочки в фазу ранней диастолы, общий диастолический объем, объем крови, изгоняемый желудочками в фазу быстрого изгнания, объем крови, изгоняемый желудочками в фазу медленного изгнания, объем крови, перекачиваемый аортой (как перистальтический насос) [1, с. 211].

Комплексный подход к лечению заключался в коррекции жизненно важных функций, поддержании гомеостаза, выполнение алгоритма коррекции ВЧД [6, с. 62; 7, с. 342].

Хирургические вмешательства проводились в следующем объеме: первичная хирургическая обработка ран, трепанация по очагу повреждения, декомпрессивная трепанация черепа, реконструктивные операции на лицевом отделе черепа, органах брюшной полости, дренирование плевральной полости, проведение различных типов остеосинтеза.

После завершения стабилизации состояния пациентов с нарушением сознания, гемодинамики и дыхания, проводили от 8 до 15 сеансов гипербарической оксигенации, время экспозиции от 40 до 60 мин при давлении 1,2-1,3 AТА (0,2 - 0,3кгс/см2), при этом компрессия и декомпрессия проводилась со скоростью 0,05 кгс/см2/мин [1, с. 320-321; 7, с. 235-236].

Статистическая обработка результатов исследований проводилась на ПЭВМ Pentium III-500, с помощью программ Exel 2016, стандартного пакета STATISTICA for Windows ver 10.0 SPSS Inc. с использование непараметрических критериев.

Результаты. Проанализировав полученные баллы и сопоставив их с табличными значениями шкал по Европейской и Российской модификации шкал Abbreviated Injury Scale Score(AIS) и Injury Severity Score (ISS), которые отличаются друг от друга границами анатомических областей, мы получили, что 40,3\% детей имели легкую степень повреждений, 19,8\% - повреждения средней степени тяжести, $17 \%$ - тяжелые повреждения, 10,9\% - крайне 
тяжелые повреждения, 12\% - не явились сочетанными по модификации шкалы Injury Severity Score мирового сообщества, тогда как по российской модификации в данной группе оказались лишь 4\% детей.

При оценке результатов исходов лечения отметили, что у 210 детей $(83,9 \%)$ - наступило полное выздоровление без неврологического дефицита, у $28(11 \%)$ - неполное выздоровление с минимальными неврологическими нарушениями, у $7(2,7 \%)$ - неполное выздоровление с грубыми неврологическими нарушениями 6 детей $(2,3 \%)$ - летальный исход.

После сеансов гипербарической оксигенации было выявлено значительное улучшение метаболизма мозговых структур, а также других органов и систем, подтвержденных методами объективного осмотра, лабораторными данными, результатами инструментального обследования.

При расшифровке параметров центральной гемодинамики у 45\% детей были выявлены снижение ударного объема, минутного объема кровообращения на 25-30\%, объем крови, притекающий в желудочки в фазу ранней диастолы на 20-24\%, тонус восходящей аорты 15-20\%, объем крови изгоняемый желудочками в фазу быстрого и медленного изгнания в виде снижения данных показателей от $9 \%$ до $38 \%$ от нормы. Параметр гемодинамической нагрузки на предсердия, напротив, был повышен от 6\% до $35 \%$.

ВыВоды.

1. Шкалы AIS и ISS несут большую диагностическую и прогностическую ценность для оценки состояния ребенка при сочетанной травме, а также для составления плана лечения.

2. Более чувствительной является российская модификация шкал AIS и ISS, так как представлена более широким диапазоном анатомических областей тела.

3. У детей с сочетанной травмой, сопровождающейся шоком, отмечаются значительные нарушения параметров ЦГ, включая показатели ударного объема, ранней диастолы, сократительной способности миокарда.

4. Определение параметров ЦГ аппаратом «Кардиокод» позволяет у 11\% пострадавших диагностировать шок на ранних стадиях его развития.

5. Комплексное лечение больных с тяжелой сочетанной травмой, при наличии ЧМТ различной степени тяжести, а так же применение новых методов диагностики, своевременная доставка больных в оснащенный необходимым оборудованием стационар, внедрение гипербарической 
оксигенации в остром периоде травмы способствуют улучшению результатов лечения пострадавших детей и сокращению летальных исходов до 2,3\%.

Заключение. От правильно и оперативно организованной работы медицинского персонала зачастую зависит жизнь больного. На скорость принятия решений влияют множество факторов, но главный - тяжесть состояния пациента. Шкалы AIS и ISS являются простыми и удобными в применении, основываются на объективных показателях, а также дают достоверный результат, что важно при наличии экстренной патологии. Они позволяют в короткие сроки дать заключение о тяжести состояния пациента, помогая тем самым выработать план лечения и приступить к его осуществлению.

\section{Список литературы}

1. Вечёркин В.А., Особенности травматического шока у детей : дис. док. мед. наук. / Вечёркин Владимир Александрович ; Москва, 2006. 310 л.

2. Васильева И.В., Карасева О.В., Чернышева Т.А., Тимофеева А.Ю. и др. Исследование валидности шкал оценки тяжести повреждения и состояния при тяжелой сочетанной травме у детей // Мед. алфавит. 2014. Т. 1, № 5. C. $12-15$.

3. Агаджанян В.В., Кравцов С.А., Железнякова И.А., Корнев А.Н., Пачгин И.В. Интеграция критериев степени тяжести политравмы с Международной классификацией болезней. Политравма 2014, с. 6-14;

4. Березка Н.И., Литовченко В.А., Гарячий Е.В., Лапшин Д.В., Морозова Ю.В. Оптимизация хирургической тактики лечения пострадавших с политравмой с использованием шкал оценки тяжести состояния и повреждений. Научные ведомости БелГУ. Медицина. Фармация 2014; 25(4): $116-119$.

5. Семенов А.В., Сороковиков В.А. Шкалы оценки тяжести и прогнозирования исхода травмы // Политравма. 2016. № 2. С. 80-90.

6. Цибин Ю.Н., Гальцева И.В., Рыбаков И.Р., Фролов Г.М. Балльная оценка шокогенности травм в зависимости от их локализации и характера // Травматический шок. Л., 1977. Вып. 4. С. 60-62.)

7. Щедренок В.В., Яковенко И.В., Могучая О.В. Клиникоорганизационные аспекты сочетанной черепно-мозговой травмы. СПб., 2010. 434 c. 